TITLE:

\title{
Vacuum ultraviolet-induced surface modification of cyclo-olefin polymer substrates for photochemical activation bonding
}

\section{AUTHOR(S):}

KIM, Young-Jong; TANIGUCHI, Yoshinao; MURASE, Kuniaki; TAGUCHI, Yoshihiro; SUGIMURA, Hiroyuki

\section{CITATION:}

KIM, Young-Jong ... [et al]. Vacuum ultraviolet-induced surface modification of cyclo-olefin polymer substrates for photochemical activation bonding. Applied Surface Science 2009, 255(6): 3648-3654

\section{ISSUE DATE:}

2009-01-01

URL:

http://hdl.handle.net/2433/97891

\section{RIGHT:}

Copyright (C) 2008 Elsevier B.V.; この論文は出版社版でありません。引 用の際には出版社版をご確認ご利用ください。; This is not the published version. Please cite only the published version. 


\title{
Vacuum Ultraviolet-Induced Surface Modification of Cyclo-olefin
}

\section{Polymer substrates for Photochemical Activation Bonding}

Young-Jong KIM, Yoshinao TANIGUCHI*, Kuniaki MURASE, Yoshihiro TAGUCHI*, and Hiroyuki SUGIMURA*

Department of Materials Science and Engineering, Kyoto University,

Yoshida-hommachi, Sakyo-ku, Kyoto 606-8501, Japan

*Present address: ALPS ELECTRIC, Business Development HQ,

Production Engineering Development Center 136-1, Kitahara, Tsukanome,

Furukawa, Osaki-City, Miyagi-Pref, 989-6225, Japan

*E-mail address : hiroyuki.sugimura@ materials.mbox.media.kyoto-u.ac.jp

\begin{abstract}
The surfaces of cyclo-olefin polymer (COP) were treated using vacuum ultraviolet (VUV) light at $172 \mathrm{~nm}$ in wavelength in order to improve its wettability and adhesion properties. The effect of the VUV-light treatment with variable conditions was studied, and then the condition was
\end{abstract}


optimized. The chemical and physical properties of the sample was examined by using water contact angle measurements, X-ray photoelectron spectroscopy, fourier transform infrared spectroscopy, and atomic force microscopy. The VUV treatment of an COP sample was carried out by placing the sample in air and then irradiating the sample surface with a Xe-excimer lamp. At that time, The surface terminal groups were oxidized into the functional groups (detected as $\mathrm{C}-\mathrm{O}, \mathrm{C}=\mathrm{O}$, and $\mathrm{COO}$ components) readily on $\mathrm{COP}$ surfaces. The introduction of oxygen functional groups formed hydrophilic COP surfaces. We investigated how the oxygen functional groups are formed on the COP surface from the viewpoint of different distances between the lamp and the sample. The dependence of oxygenation extent on different experimental parameters of VUV irradiation distance or treatment duration is measured by atomic ratio $\mathrm{O} 1 \mathrm{~s} / \mathrm{C} 1 \mathrm{~s}$ of XPS spectra and $[\mathrm{C}=\mathrm{O}] /[\mathrm{C}-\mathrm{H}]$ area ratio of FTIR-ATR spectra. It was shown that the surface property of COP samples, such as hydrophilicity and functionalization, were improved 
remarkably after VUV treatment with suitable conditions. A much higher concentration of oxygen functional groups was observed for distance 5 $\mathrm{mm}$ than for the corresponding distance $30 \mathrm{~mm}$ at the same extent of VUV-light treatment. VUV-light treatment also has a more obvious effect on the short irradiation distance. In both cases, however, the concentration of oxygen functional groups changes remarkably. It was concluded that VUV treatment is a promising technique to modify COP surface property. KEYWORDS: surface modification, excimer lamp, vacuum ultraviolet (VUV), oxygen functional groups

\section{Introduction}

Today, cyclo-olefin polymer (COP) resins are used in a variety of applications according to their various properties and low costs. COP properties such as excellent transparency, high heat resistance, low water absorbency, stable and guaranteed refractive index, and low birefringence are fully utilized in applications, especially for camera lenses/prisms, 
lenses for cameras incorporated into mobile phones, pick-up lenses, and $\mathrm{Fq}$ lenses for laser beam printers. Also, the COP is used in such applications as medical vials, syringes, optical lab test cells, and syringes pre-filled with pharmaceutical content. The COP is especially suitable for use in medical devices that undergo autoclave sterilization at $121{ }^{\circ} \mathrm{C}$. The market for COPs is growing every year due to their excellent properties, primarily in optical applications. ${ }^{1}$

Extensive work to develop practical and economical method for surface modification of COP has been carried out by many workers. For improvement of adhesivity, dyeability, and wettability, surface photografting modification in gas-phase or liquid-phase has attracted wide attention. $^{2-7}$ Especially, adhesion is a critical design feature of many commercially available products. In order to obtain better adhesion property, it is necessary to improve the adhesive chemical bond at the interface. This is possible by increasing the distribution of polar functional groups at the surface. An appropriate surface treatment is 
required for this purpose.

Polymeric materials, especially in continuous format, i.e. films, have been largely treated through different oxidative process, such as corona discharge, ${ }^{8-11}$ plasma etching, ${ }^{12,13}$ ultraviolet radiation, ${ }^{14,15}$ chemical solutions, ${ }^{16-18}$ etc. The resulting changes in surface composition, morphology, and surface energy can improve adhesive bonding, wettability, biocompatibility, and many other surface-related properties. Although it is desirable to give new functions to polymer surfaces, it is also important to modify polymer material surfaces without affecting their bulk characteristics, such as mechanical, thermal and other intrinsic properties. ultraviolet radiation is a good method in this respect because ultraviolet radiation interacts with the polymer surface and not with its bulk. Also, ultraviolet radiation is a very efficient, economical and potentially practical oxidative process for modifying polymer surface. Particularly, it is widely known that the energy of photons becomes stronger as its wavelength becomes shorter. This enables it to 
cause chemical reactions unattainable by a conventional UV light and allows acceleration of the reaction speed. In addition, short-wavelength [vacuum ultraviolet (VUV), $\lambda<200 \mathrm{~nm}$ ] radiation is believed to play an important role in the near-surface chemistry of plasma-treated polymers. ${ }^{19,20}$ One possible advantage of VUV photochemistry over its plasma counterparts may be that a more specific surface chemistry is achieved using monochromatic radiation because of more specific and selective (photo) chemistry both on the solid surface and in the gas phase. $^{21}$

For this study, we investigated whether VUV-light treatment modifies the COP surface to produce a hydrophilic surface, whether the chemical components on the COP surfaces are modified by VUV-light treatment, and whether the rates of the introduction of functional groups on COP surfaces by VUV-light treatment differ or not, according to the influence of experimental parameters such as VUV irradiation distance and treatment duration on the extent of surface photochemical 
modification. The chemical analysis of polymer surfaces has provided a fruitful realm for the application of X-ray photoelectron spectroscopy (XPS). XPS is now well-known for the unique qualitative and quantitative surface information derived from core and valence level spectra. However, when utilized alone, XPS has some major weaknesses. We have been active in the extension of surface analysis of polymers by fourier transform infrared spectroscopy (FTIR). Especially, using XPS and FTIR, analyzed the generation of hydroxyl, carbonyl, and carboxyl groups on the surface of COP samples treated with VUV-light, and it was shown that both XPS and FTIR complemented each other and were useful in analyzing the changes in chemical composition due to surface oxidation.

\section{Experimental}

\subsection{Materials}

The sample used in this study was a transparent cyclo-olefin 
polymer (COP) supplied by Alps Electric (Furukawa, Osaki-City, Miyagi-Pref, Japan) with a thickness of $1 \mathrm{~mm}$. Samples were prepared for the VUV-light treatment and, front this, samples of different dimensions were cut for different measurements. Detailed properties of the COP have already been reported.

\subsection{VUV-light treatment}

A schematic of the VUV-irradiation apparatus is shown in Figure.

1. We used an excimer lamp as a source of VUV light at a wavelength of $172 \mathrm{~nm}$ (Ushio., UER20-172V; intensity at the lamp window, $10 \mathrm{~mW}$ $\mathrm{cm}^{-2}$ ) as a light source. This lamp consists of two (inner and outer) quartz glass tubes. The metal electrode is mounted within the inner tube, while the metal mesh electrode is mounted outside of the outer tube. The quartz glass tubes are filled with a discharge gas. The COP samples were placed on the sample stage. In our VUV-light-exposure system, the chamber was filled with ambient air, and the distance between the lamp window and the 
sample surface was fixed at 5 and $30 \mathrm{~mm}$. Since oxygen molecules strongly absorb VUV light at $172 \mathrm{~nm}$, the VUV light is attenuated when propagating through an air layer with a certain thickness. The optical absorption coefficient of the VUV light at wavelength $172 \mathrm{~nm}$ in ambient air with an oxygen partial pressure 0.2 atm was reported to be in the range of $10-15 \mathrm{~cm}^{-1} \mathrm{~atm}^{-1},{ }^{22}$ indicating that the transmittance the light through a $10 \mathrm{~mm}$-thick air layer is calculated to be in the range of $5-13 \%$, and we also observed measured the value was about $10 \%$. Therefore, the transmittance for $5 \mathrm{~mm}$ is estimated to be less than $50 \%$, which means that the light intensity at the COP surface is less than $5 \mathrm{~mW} \mathrm{~cm}$. At a distance of $5 \mathrm{~mm}$, the sample surface was directly irradiated with the VUV light emitted from the lamp window, although there was a absorption loss with about 50\%. Simultaneously, the sample surface was exposed to active oxygen species generated in the space just on the sample surface. Both the reactions, that is, VUV-excitation of the COP surface and the oxidation of the COP surface with the active oxygen, were 
considered to proceed on the sample surface. In contrast, the transmittance for $30 \mathrm{~mm}$ is estimated to be less than $0.1 \%$, which means that the light intensity at the ODS-SAM surface is less than $0.010 \mathrm{~mW}$ $\mathrm{cm}^{-2}$. In other words, at the distance of $30 \mathrm{~mm}$, VUV light was absorbed almost completely by atmospheric oxygen molecules, yielding active oxygen species such as ozone and atomic oxygen, hence no substantial amount of VUV-light reached the sample surface. The direct irradiation of COP surfaces with VUV photons is not expected in the system of an air layer of $30 \mathrm{~mm}$, and only the VUV-light-generated active oxygen can participate in the surface modification of the COP.

\subsection{Chemical and physical properties analysis}

After VUV-light treatment, photochemical effects of VUV-light treatments on the COP surfaces were investigated using a combination of analytical techniques. The static water contact angles of the sample surfaces were measured with a contact angle meter (Kyowa Interface 
Science, CA-X) in an atmospheric environment; here, we fixed the size of water droplets at about $1.5 \mathrm{~mm}$ in diameter. At least four different measurements on the sample surfaces were obtained and the average values for water contact angles were calculated. The chemical bonding states of each sample were examined by X-ray photoelectron spectroscopy (XPS; Kratos Analytical, ESCA-3400) using a Mg Ka X-ray source with $10 \mathrm{~mA}$ in emission current and $10 \mathrm{kV}$ in accelerating voltage. The background pressure in the analytical chamber was $8.0 \times 10^{-7} \mathrm{~Pa}$. The X-ray spot diameter was $6 \mathrm{~mm}$. The binding energy scales were referenced to $285.0 \mathrm{eV}$ as determined by the locations of the maximum peaks on the $\mathrm{C} 1 \mathrm{~s}$ spectra of hydrocarbon $\left(\mathrm{CH}_{x}\right)$, associated with adventitious contamination. The $\mathrm{C} 1 \mathrm{~s}$ and $\mathrm{O} 1 \mathrm{~s}$ spectra were decomposed by fitting a Gaussian-Lorentzian mixture function (mixture rate, 20 : 80). Surface modification process of COP samples were also monitored by quantitative fourier transform infrared spectroscopy (FTIR; Digilab Japan Co., Ltd, Excalibur FTS-3000). We used a single reflection ATR 
(attenuated total reflection) mode for measurement of the samples. The ATR IR spectra were obtained with $65^{\circ}$ of incident angle, and hemispherical Ge ATR crystal with diameter of $2.5 \mathrm{~cm}$ (internal reflection element, from Harrick Scientific). IR Spectra were measured in a dry atmosphere of a sample compartment purged with nitrogen and were referenced to background spectra determined under the same conditions. All spectra were measured at a resolution of $4 \mathrm{~cm}^{-1}$ and with 1024 times of scan cycles. The morphology and surface roughness of the samples were measured by an atomic force microscopy (AFM; SII Nanotechnology, SPA-300HV + SPI-3800N) in tapping mode at a scan rate of $0.5 \mathrm{~Hz}$, using silicon cantilever probe (Seiko Instruments Inc., SI-DF20, force constant of $15 \mathrm{~N} \mathrm{~m}^{-1}$ ). From the analysis of the images, the root-mean-squared roughness $\left(\mathrm{R}_{\mathrm{RMS}}\right)$ for the topographic profiles measured on $5 \times 5 \mu \mathrm{m}^{2}$ images was evaluated.

\section{Results and Discussion}


3.1. Water contact angle on COP sample surfaces treated with the direct and remote $V U V$-light

We investigated whether VUV-light treatment modifies COP surfaces to make the COP surface hydrophilic. The changes of water contact angles on the COP surface treated with VUV-light for irradiation distance 5 and $30 \mathrm{~mm}$ are shown in Figure 2, respectively. As can be observed, the COP surface treated with VUV-light for irradiation distance $5 \mathrm{~mm}$ became hydrophilic more rapidly than that for irradiation distance $30 \mathrm{~mm}$. In case of distance $5 \mathrm{~mm}$, water contact angles show large decrease in the modifying hydrophilic surfaces with increasing VUV irradiation time but level off from $20 \mathrm{~min}$. After $20 \mathrm{~min}$, the water contact angle settled at zero. In contrast, in case of distance $30 \mathrm{~mm}$, it gradually decreased but level off from $40 \mathrm{~min}$. Finally, the water contact angle remained at approximately $14^{\circ}$. Thus, for VUV irradiation time of $5 \mathrm{~min}$ the water contact angle loss is around 78 and $44 \%$ for distance 5 and 30 
mm, respectively. Results showed that, on the COP surface, the surface contact angle made by VUV-light treatment decreased to modify hydrophilically. It was expected that the COP surfaces treated by VUV-light treatment were introduced by the oxygen functional groups.

\subsection{Chemical composition of direct and remote VUV-light treated COP} sample surface

This VUV-irradiated surface chemical conversion of COP was studied in more detail using XPS. By means of XPS measurement, we investigated the dependency of surface oxygenation of COP on different experimental conditions, such as VUV irradiation distance and treatment duration. We can use the atomic ratio of intensity of $\mathrm{O} 1 \mathrm{~s}$ to that of $\mathrm{C} 1 \mathrm{~s}$ $(\mathrm{O} 1 \mathrm{~s} / \mathrm{C} 1 \mathrm{~s})$ as a measure of the surface oxygenation extent. The increase in the extent of surface oxidation with VUV irradiation time is shown in Figure 3. The initially faster oxidation in case of distance $5 \mathrm{~mm}$ shows that the atomic ratio of $\mathrm{O} 1 \mathrm{~s} / \mathrm{C} 1 \mathrm{~s}$ can reach a level which changes the 
surface composition distinctly in a short time (on the order of one minute). The most reasonable explanation for these results is the assumption that active oxygen species oxide intact COP only with a low rate. Obviously, a photolytic activation is needed for the increase of COP oxidation. In our previous paper, ${ }^{23,24}$ we investigated the vacuum ultraviolet (VUV) photodegradation of alkyl monolayers in the presence of atmospheric oxygen molecules. Here, VUV light of $172 \mathrm{~nm}$ in wavelength excites atmospheric oxygen molecules, resulting in the generation of ozone molecules as well as oxygen atoms in singlet and triplet states $[\mathrm{O}(1 \mathrm{D})$ and $\mathrm{O}(3 \mathrm{P})$, respectively], as described in the following equation. ${ }^{25}$

$$
\mathrm{O}_{2}+h v \rightarrow \mathrm{O}(1 \mathrm{D})+\mathrm{O}(3 \mathrm{P})
$$

Since these active oxygen species, particularly O(1D), have strong oxidative reactivity. In case of distance $5 \mathrm{~mm}$, the sample surface was directly irradiated with VUV light while the sample surface was exposed to active oxygen species. Therefore, in addition to the oxidation 
of the sample surface with the active oxygen, a VUV excitation of the sample surface might be induced. The overall oxidation is expected to be autoaccelerating. And this point is very important for commercial practice. From Figure 3, an optimum experimental condition for irradiation distance 5 and $30 \mathrm{~mm}$ can be found. This is that the VUV irradiation time is $40 \mathrm{~min}$, respectively.

In addition to providing the total heteroatom concentration on the surfaces of VUV-treated COP presented above, XPS was also used to characterize their chemical bonding states. Remarkable differences between distance $5 \mathrm{~mm}$ and distance $30 \mathrm{~mm}$ were found not only in the rate of oxygen incorporation and the final oxygen concentration but also in the evolution of the oxygen functional groups. Figures 4 and 5 shows the C1s and O1s XPS spectra of COP samples prior to and after VUV irradiation for 5, 10, 40, and $60 \mathrm{~min}$. In Figures 4 and 5, the spectra for the untreated sample are also shown figure for comparison with the VUV-light treatment results. The tail on the high binding energy side of 
the main $\mathrm{C} 1 \mathrm{~s}$ peak for COP shows that oxygen incorporation into the COP surfaces gave rise to a variety of functional groups. These $\mathrm{C} 1 \mathrm{~s}$ peaks can be decomposed into four main components at 285.0 (C-H groups), 286.5 (C-O groups), 288.0 ( $\mathrm{C}=\mathrm{O}$ groups), and $289.5 \mathrm{eV}(\mathrm{COO})$. The O1s peaks can be decomposed into two peaks with binding energies of 532.4 and $533.8 \mathrm{eV}$, respectively. The peaks are assigned as follows: $\mathrm{O} 1 \mathrm{~s} 532.4 \mathrm{eV}$ $(\mathrm{C}=\mathrm{O}$ or $\mathrm{C}-\mathrm{O}$ groups $)$ and 533.8 eV $(\mathrm{O}=\mathrm{C}-\underline{\mathrm{O}}-\mathrm{H}$ or $\mathrm{O}=\mathrm{C}-\underline{\mathrm{O}}-\mathrm{C}$ groups). From XPS analysis, it can be seen that after VUV-light treatment, there appeared oxygen functional groups such as carbonyl, ether, and carboxyl in COP surface. A much higher concentration of oxygen functional groups was observed for distance $5 \mathrm{~mm}$ than for the corresponding distance $30 \mathrm{~mm}$ at the same extent of VUV-light treatment. In case of distance $30 \mathrm{~mm}$, prolonged VUV-light treatment $(>10 \mathrm{~min})$ can result in the appearance of the COO components. VUV-light treatment also has a more obvious effect on the short irradiation distance. By VUV irradiation for 5, 10, and $40 \mathrm{~min}$, the 
amount of carbon on the sample decreased, whereas the amount of oxygen on the sample increased. XPS analysis as a function of the VUV-light treatment duration also indicates a progressive functionalization. The $\mathrm{C} 1 \mathrm{~s}$ atomic percentage data summarized in Table I and II shows progressive increases in the surface densities of oxygen functional groups (detected as $\mathrm{C}-\mathrm{O}, \mathrm{C}=\mathrm{O}$, and $\mathrm{COO}$ components) with VUV-light irradiation until 40 min as confirmed by Figure 3. However the differences between the samples with VUV irradiation times of 40 and 60 min are not evident. It is remarkable that the functionalization of COP by VUV-light treatment remains almost constant for VUV irradiation times higher than 40 min. The increase of amount of oxygen functional groups are in agreement with the reduction of the water contact angles showed by Figure 2. These results indicate that surface modification with VUV-light treatment is effective in enhancing their functionalization.

For the surface chemical-analysis obtained by XPS, we also employed a supplemental measurement by using FTIR. The FTIR-ATR 
spectra of untreated and treated COP are presented in Figure 6 and 7, respectively. Given that the sampling depth of the present FTIR-ATR technique $(0.13 \mu \mathrm{m}$ and below $)$ is large compared with the estimated depth of VUV-light treatment effects. To highlight the chemical changes in the surface, the untreated sample are shown. As we can see, the VUV-light treatment introduces three new IR bands such as $\mathrm{O}-\mathrm{H}, \mathrm{C}=\mathrm{O}$, and $\mathrm{C}-\mathrm{O}$ valence vibration. A very broad between 3750 and $3050 \mathrm{~cm}^{-1}$, centered at about $3450 \mathrm{~cm}^{-1}$, can be attributed to the $\mathrm{O}-\mathrm{H}$ stretch in alcohols and phenols. A relatively sharp band between 1897 and $1519 \mathrm{~cm}^{-1}$ has a doublet structure, subpeaks being centered at 1716 and $1624 \mathrm{~cm}^{-1}$, respectively. This feature can be assigned to $\mathrm{C}=\mathrm{O}$ stretch in aliphatic ketones $\left(1725-1705 \mathrm{~cm}^{-1}\right), \quad \mathrm{C}=\mathrm{C}$ and $\mathrm{C}=\mathrm{O}$ in unsaturated ketones $\left(1705-1665 \mathrm{~cm}^{-1}\right), \mathrm{C}=\mathrm{O}$ stretch in primary $\left(1680-1519 \mathrm{~cm}^{-1}\right)$. A broad band, between 1290 and $1180 \mathrm{~cm}^{-1}$, can be assigned to $\mathrm{C}-\mathrm{O}-\mathrm{C}$ antisymetric stretch in esters. A broad band, between 1000 and $900 \mathrm{~cm}^{-1}$ with a peak at $940 \mathrm{~cm}^{-1}$, can be assigned to $\mathrm{CH}$ out-of-plane deformation 
(1000-950 $\left.\mathrm{cm}^{-1}\right), \mathrm{CH}_{2}$ out-of-plane wagging $\left(950-900 \mathrm{~cm}^{-1}\right)$ in vinyl $\left(-\mathrm{CH}=\mathrm{CH}_{2}\right)$, and $\mathrm{CH}$ out-of-plane deformation $\left(980-955 \mathrm{~cm}^{-1}\right)$ in vinylene $(-\mathrm{CH}=\mathrm{CH}-)$ with a high level of confidence. As above mentioned, Figure 6 and 7 shows the increase of the $\mathrm{C}=\mathrm{C}$ double bonds concentration in a sample surface. This can be explained as follows: $\mathrm{C}=\mathrm{C}$ double bonds are formed by the abstraction of hydrogen, known as the dominant mechanism during VUV irradiation of hydrocarbon polymers. ${ }^{26-28}$ Figure 6 and 7 shows that the vibrational bands that are significantly perturbed as a function of VUV irradiation time are the carbonyl band vibrations at about $1897-1519 \mathrm{~cm}^{-1}$. It should be pointed out that no spectrum is free from carbonyl band vibrations except for non-treated sample, but the intensity of this band increased relatively from one sample to another as a function of VUV irradiation time. Here, in the FTIR analysis, we mean by the word intensity the height of the peak and not the area. The carbonyl band area is measured relatively to the hydrocarbon $(\mathrm{C}-\mathrm{H})$ band area, and the result is shown in Figure 8, as a function of VUV irradiation time. In this 
figure, a substantial increase in the $[\mathrm{C}=\mathrm{O}] /[\mathrm{C}-\mathrm{H}]$ area ratio until $40 \mathrm{~min}$ can be observed. This fact corroborates the activation/functionalization effect of VUV-light treatment on the COP surface. However the differences between the samples with VUV irradiation times of 40 and 60 min are not evident. It is remarkable that the functionalization of COP by VUV-light treatment remains almost constant for VUV irradiation times higher than $40 \mathrm{~min}$. As discussed above (XPS results) with $\mathrm{O} 1 \mathrm{~s} / \mathrm{C} 1 \mathrm{~s}$ atomic ratio, Figure 3 showed an outstanding increase in the $\mathrm{O} 1 \mathrm{~s} / \mathrm{C} 1 \mathrm{~s}$ atomic ratio at the time of VUV light until $40 \mathrm{~min}$. An exact agreement between XPS and FTIR analysis can be expected though they have different sampling depths. The large increase in the $[\mathrm{C}=\mathrm{O}] /[\mathrm{C}-\mathrm{H}]$ area ratio thus means that the non-treated sample has been oxidized largely, while the outermost layers have lost part of their oxygen-containing moieties, as evidenced by the XPS $\mathrm{O} 1 \mathrm{~s} / \mathrm{C} 1 \mathrm{~s}$ atomic ratio.

\subsection{Topography of direct and remote VUV-light treated COP sample}


surface

The surface structure of the VUV-light-treated COP was monitored using AFM. AFM is a more adapted technique for the characterization of VUV treated surface, allowing to abtain a 3D representation of the surface topography and roughness measurements. Figure 9 and 10 shows topography images of COP samples prior to and after VUV irradiation time for 5, 10, 20, 40, and 60 min. As can be observed the VUV-light treatment shows an increase in smooth degree of the sample surface with an increase in the VUV irradiation time. That is, the VUV-light treatment on the sample causes changes in the surface topography. In case of distance $5 \mathrm{~mm}$, both the reactions, that is, VUV-excitation of the COP surface and the oxidation of the COP surface with the active oxygen species, promotes surface topography changes greatly; opposite to this, in case of distance $30 \mathrm{~mm}$, only by oxidation of the COP surface with the active oxygen species make difficult significant changes on the surface topography. In case of distance 
$5 \mathrm{~mm}$, particularly, the surface topography of treated COP for 5, $10 \mathrm{~min}$ shows structures like bubbles; however, for longer VUV irradiation times, there was a smooth structure without bubbles appears. This indicates the photon energy effects of $172 \mathrm{~nm}$ light with photons of $7.2 \mathrm{eV}$. In both cases, however, with increasing VUV irradiation time, the surface roughness gradually decreases. Changes in surface topography are observed, and they do contribute in a significant way to improve wettability as confirmed by Figure 2. In addition, this result suggests that surface oxidation has occurred uniformly. Consequently, the photons and active oxygen species would be the important parameters for the mechanism of surface modification of COP.

\section{Conclusions}

In this study, COP surfaces were irradiated using an excimer lamp as a source of VUV light at a wavelength of $172 \mathrm{~nm}$. There appeared oxygen functional groups such as ether, ketone, and carboxyl groups in the 
COP surface after VUV-light treatment. These groups formed hydrophilic polymer surfaces. The effects of the introduction of functional groups on COP surfaces by VUV-light treatment differed among experimental parameters such as VUV irradiation distance and treatment duration. A much higher concentration of oxygen functional groups was observed for distance $5 \mathrm{~mm}$ than for the corresponding distance $30 \mathrm{~mm}$ at the same extent of VUV-light treatment. VUV-light treatment also has a more obvious effect on the short irradiation distance. These differences in effects engendered differences in their chemical structures. The atomic ratio $\mathrm{O} 1 \mathrm{~s} / \mathrm{C} 1 \mathrm{~s}$ of XPS spectra and the $[\mathrm{C}=\mathrm{O}] /[\mathrm{C}-\mathrm{H}]$ area ratio of FTIR-ATR spectra can be taken as a measure of the degree of surface oxidation in VUV process. From above analysis, an optimum experimental condition for irradiation distance 5 and $30 \mathrm{~mm}$ can be found. This is that the VUV irradiation time is $40 \mathrm{~min}$, respectively. In particular for both cases, which appears to be quite stable against active oxygen, the photochemical activation seems to be crucial. It has also been 
shown that the reaction path can be influenced by the selection of VUV-light treatment conditions. Furthermore, from present investigation it can be seen that VUV-light treatment technology for COP surface modification appears to offer a number of advantages: 1) the equipment is simple and cheap; 2) the equipment can be safely and easily operated; 3 ) no chemical reagents are required; 4) there are no residual polluting byproducts and tedious after treatment. Therefore, it is expected that VUV-light treatment is a promising technology to modify COP surface properties in industry field.

\section{Acknowledgements}

This work was supported by KAKENHI (Grants-in-Aid for Scientific Research) and Kyoto University Global COE Program, "International Center for Integrated Research and Advanced Education in Materials

Science," from the Japan Society for the Promotion of Science (JSPS), and by the Sasakawa Scientific Research Grant from The Japan Science 
Society. 


\section{References}

1. Yamazaki, M. J. Mol. Catal. A: Chem. 2004, 213, 81.

2. Tazuke, S.; Kimura, H. Makromol. Chem. 1978, 179, 2603.

3. Allmer, K.; Hult, A.; Ranby, B. J. Polym. Sci.: Part A: Polym. Chem. 1988, 26, 2099.

4. Yamada, K.; Tsutaya, H.; Tatekawa, S.; Hirata, M. J. Appl. Polym. Sci. 1992, 46, 1065.

5. Feng, Z.; Icherenska, M.; Ranby, B. Die Angewandte Makromol. Chem. 1992, 199, 33.

6. Hamilton, L. M.; Green, A.; Edge, S.; Badyal, J. P. S.; Feast, W. J.; Pacynko, W. F. J. Appl. Polym. Sci. 1994, 52, 413.

7. Mingbo, H.; Xingzhou, H. Polym. Degrad. Stab. 1987, 18, 321.

8. Owens, D. K. J. Appl. Polym. Sci. 1975, 19, 3315.

9. Carly, J. F.; Kitze, P. T. Polym. Eng. Sci. 1980, 20, 330.

10. Iwata, H.; Kishida, A.; Suzuki, M.; Hata, Y.; Ikada, Y. J. Polym. Sci. Polym. Chem. Ed. 1988, 26, 3309. 
11. Iwata, H.; Kishida, A.; Suzuki, M.; Hata, Y.; Ikada, Y. J. Polym. Sci. Polym. Chem. Technol. 1978, 21, 483.

12. Yasuda, H.; Marsh, H. C.; Brandt, S.; Reilley, C. N. J. Polym. Sci. Polym. Chem. Ed. 1977, 15, 991.

13. Schonhorn, H.; Hansen, R. H. J. Appl. Polym. Sci. 1967, 11, 1461.

14. Hudis, M.; Prescott, L. E. J. Polym. Sci. 1972, B10, 179.

15. Hudis, M. J. Appl. Polym. Sci. 1972, 16, 2379.

16. Snogren, R. C. Adhes. Age 1969, 12(7), 26.

17. DeLollis, N. J.; Montoya, O. Adhes. Age 1963, 6(1), 32.

18. Nelson, E. R.; Kilduff, T. J.; Benderly, A. A. Ind. Eng. Chem. 1958, $50,329$.

19. Fozza, A. C.; Klemberg-Sapieha, J. E.; Wertheimer, M. R. Plasmas Polym. 1999, 4, 183.

20. Fozza, A. C.; Moisan, M.; Wertheimer, M. R. J. Appl. Phys. 2000, $88,20$.

21. Esrom, H.; Kogelschatz, U. Thin Solid Films 1992, 218, 231. 
22. Watanabe, K.; Inn, E. C. Y.; Zelikoff, M. J. Chem. Phys. 1953, 21, 1026.

23. Hong, L.; Sugimura, H.; Furukawa, T.; Takai, O. Langmuir 2003, 19, 1966.

24. Sugimura, H.; Hong, L.; Lee, K. H. Jpn. J. Appl. Phys. 2005, 44, 5185.

25. Roland, R. P.; Bolle, M.; Anderson, R. W. Chem. Mater. 2001, 13, 2493.

26. Hong, J.; Truica-Marasescu, F.; Martinu, L.; Wertheimer, M. R. Plasmas Polym. 2002, 7, 245.

27. Wilken, R.; Holländer, A.; Behnisch, J. Plasmas Polym. 2002, 7, 185.

28. Holländer, A.; Wilken, R.; Behnisch, J. Surf. Coat. Technol. 1999, 116-119, 788. 


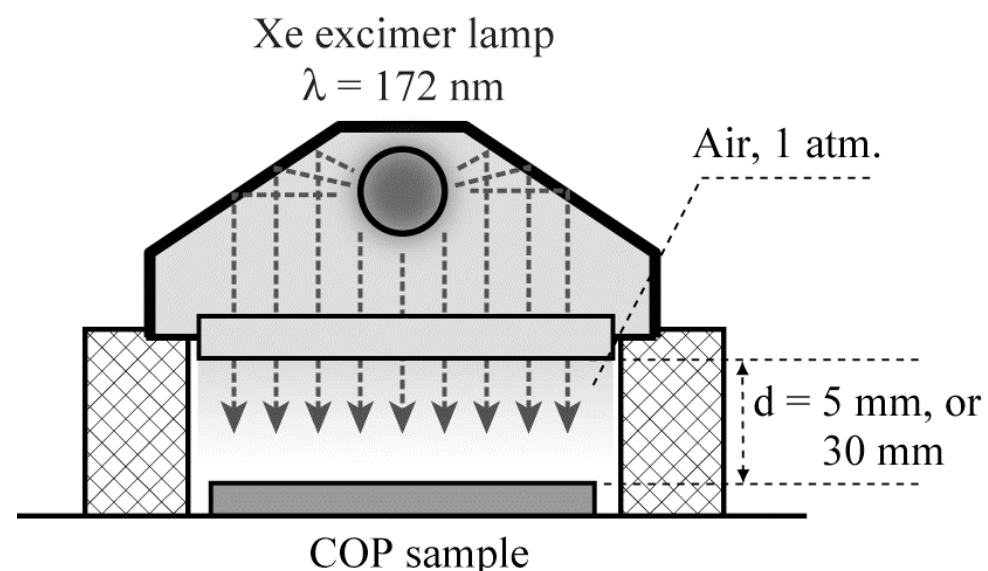

Fig. 1. Schematic illustration of VUV-irradiation apparatus. 


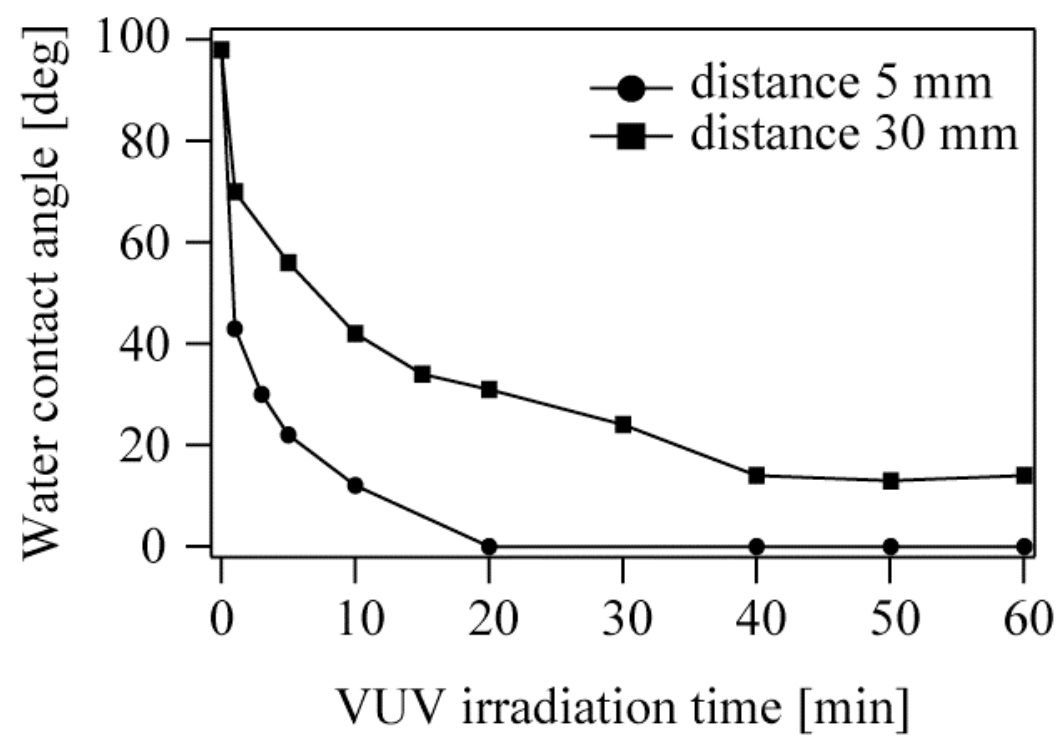

Fig. 2. Changes in water contact angles of the COP surface with irradiation time of VUV light. 


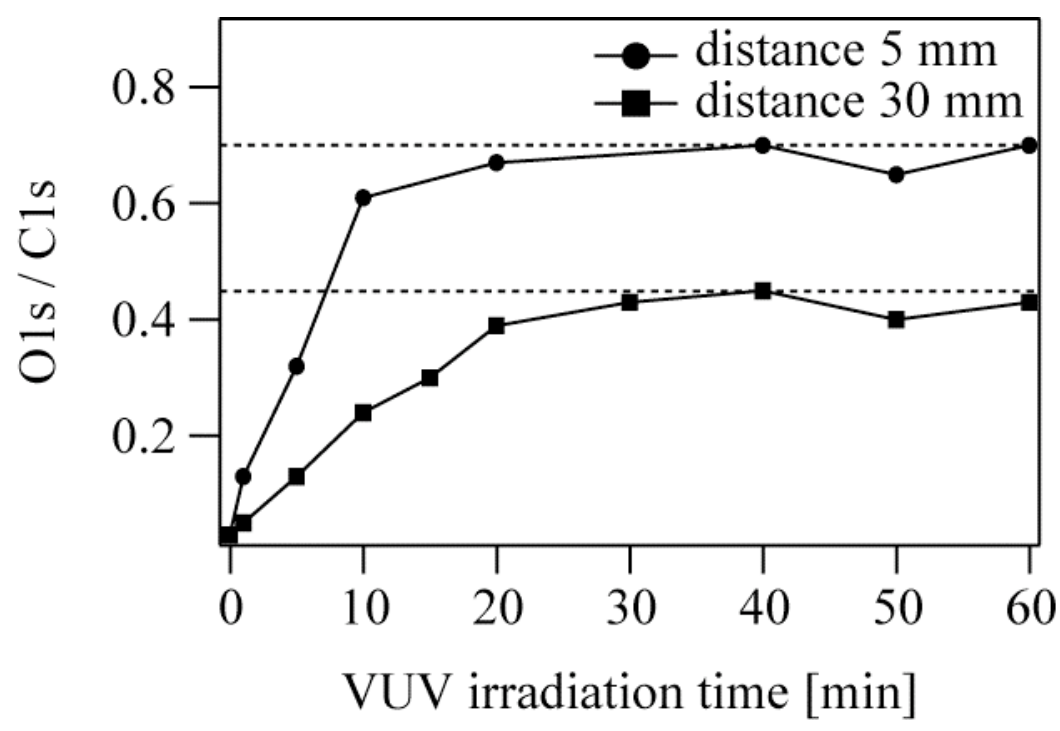

Fig. 3. Changes of O1s / C1s atomic ratio obtained from XPS. 


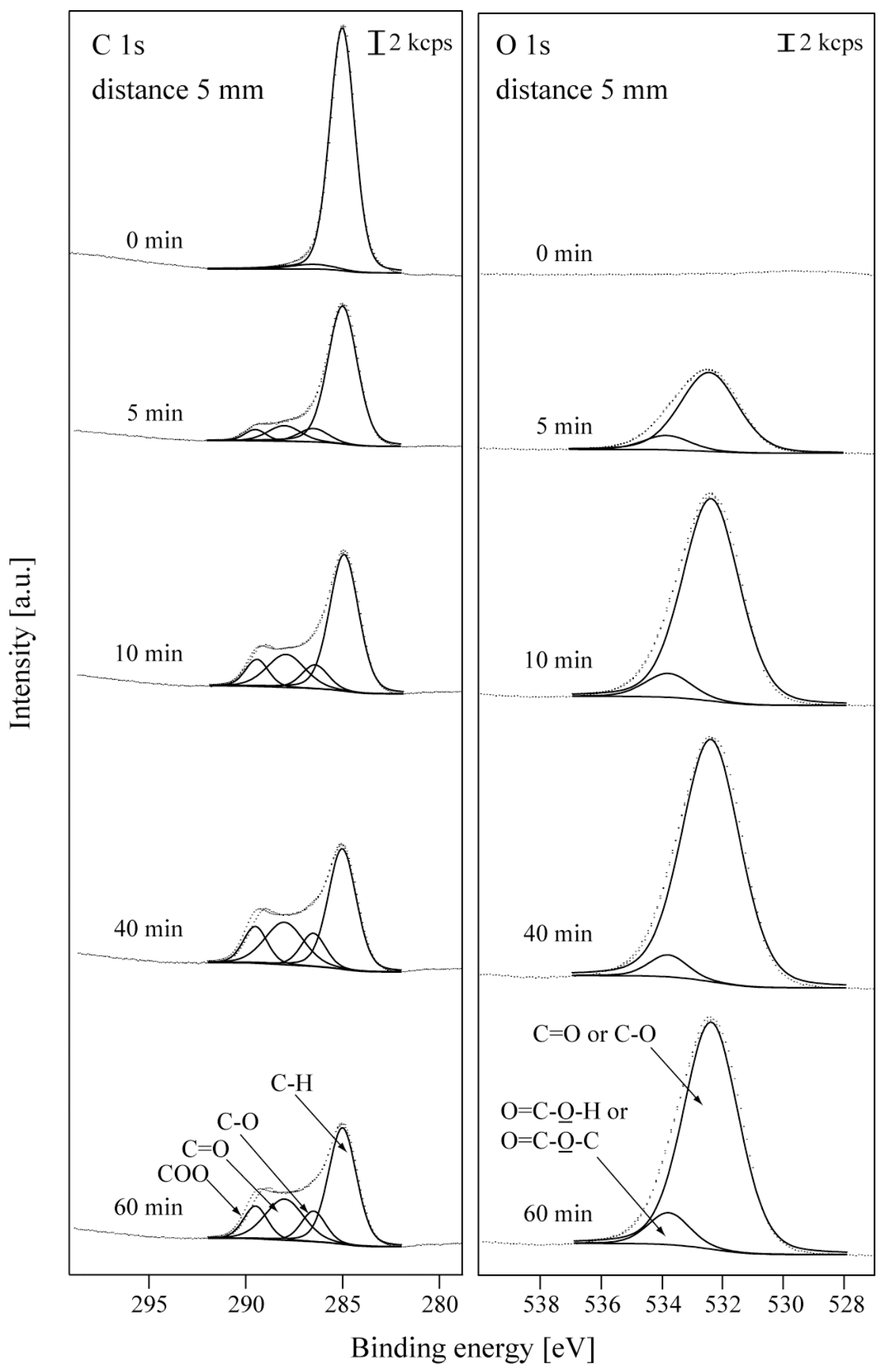

Fig. 4. Deconvoluted $\mathrm{C} 1 \mathrm{~s}$ and O1s XPS spectra obtained from COP surfaces before and after VUV irradiation at a distance of $5 \mathrm{~mm}$ for 5 - 60 $\min$. 


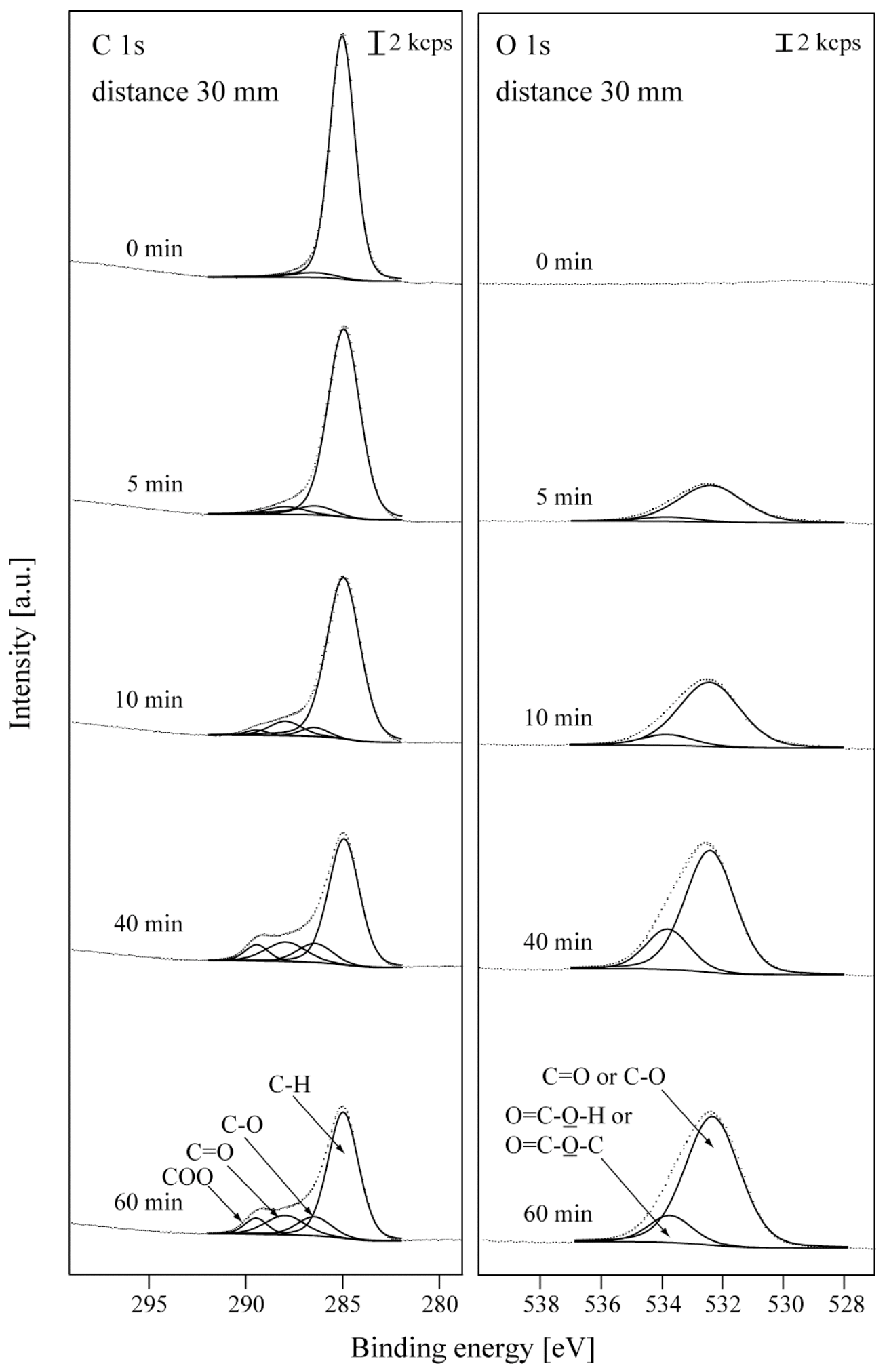

Fig. 5. Deconvoluted $\mathrm{C} 1 \mathrm{~s}$ and O1s XPS spectra obtained from COP surfaces before and after VUV irradiation at a distance of $30 \mathrm{~mm}$ for 5 - 60 $\min$. 


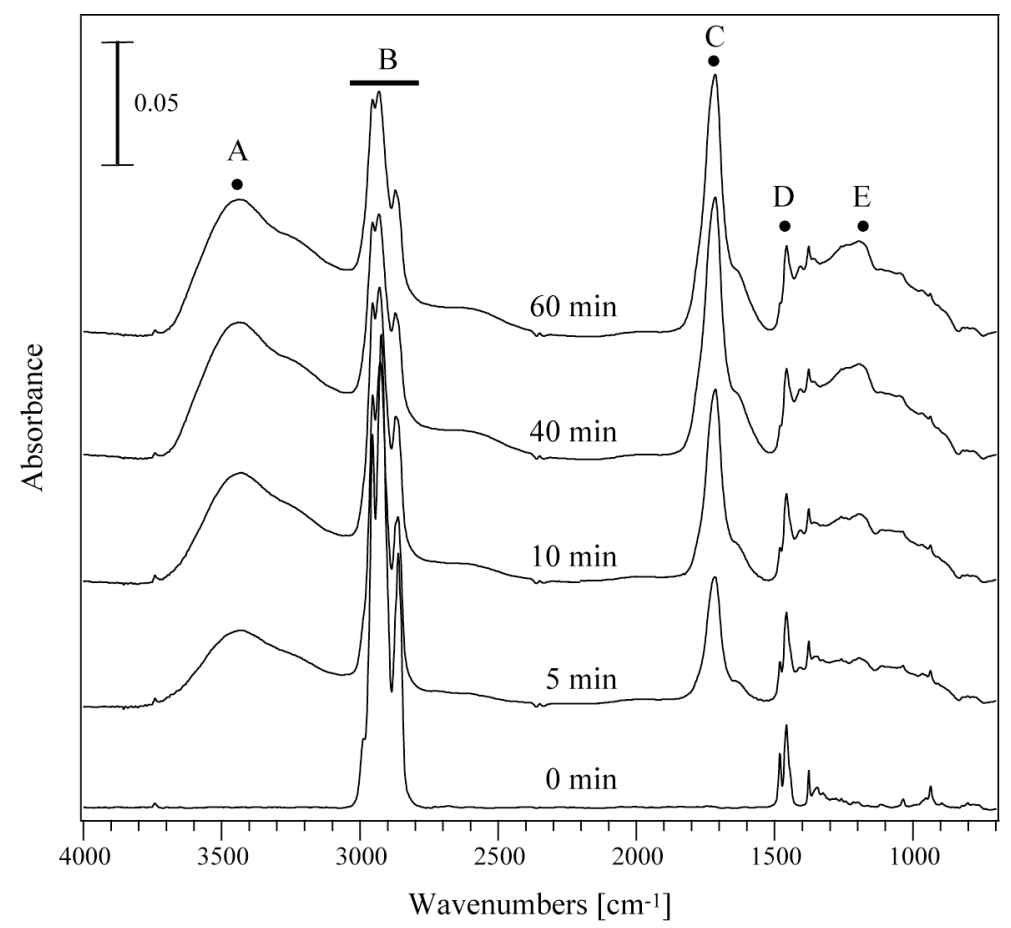

Fig. 6. FTIR-ATR spectra on COP surfaces before and after VUV irradiation at a distance of $5 \mathrm{~mm}$ for $5-40 \mathrm{~min}$ : (A) $\mathrm{O}-\mathrm{H}$ valence vibration; (B) $\mathrm{C}-\mathrm{H}$ valence vibration; (C) $\mathrm{C}=\mathrm{O}$ valence vibration; (D) $\mathrm{CH}_{2}$ deformation vibration; (E) $\mathrm{C}-\mathrm{O}$ valence vibration. 


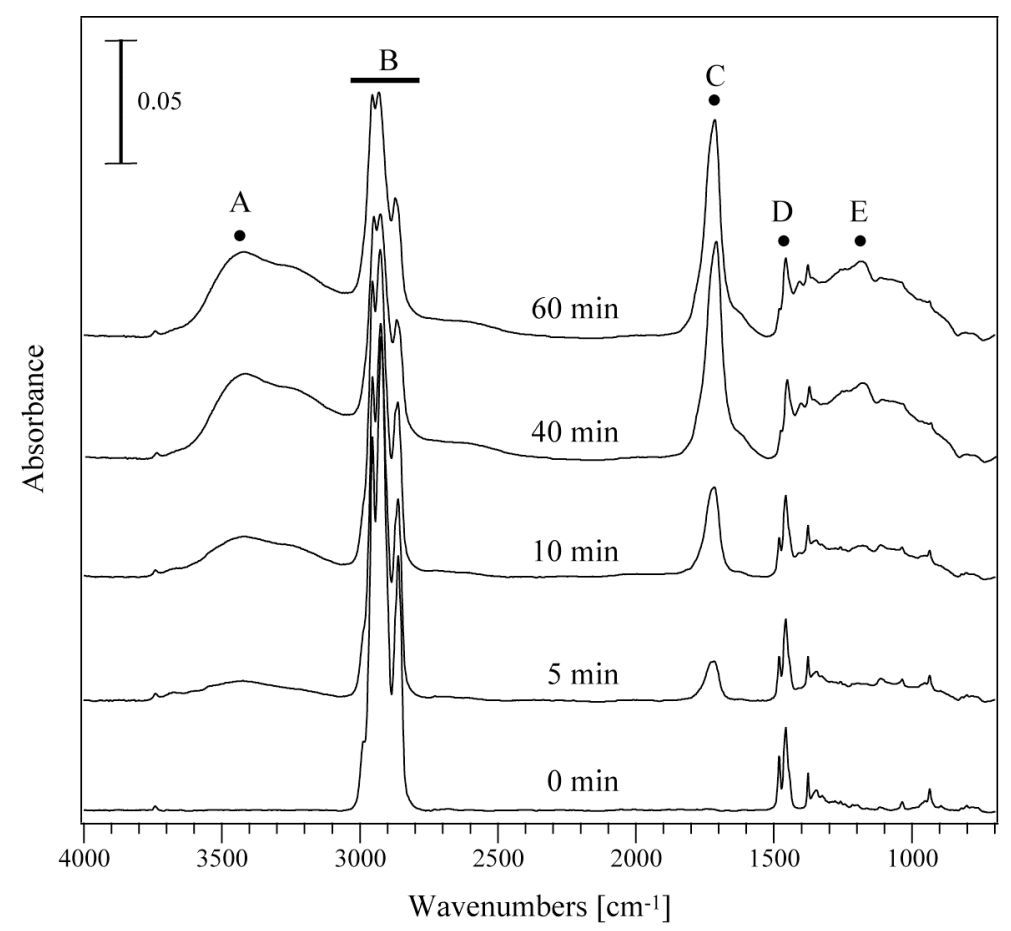

Fig. 7. FTIR-ATR spectra on COP surfaces before and after VUV irradiation at a distance of $30 \mathrm{~mm}$ for $5-40 \mathrm{~min}$ : (A) $\mathrm{O}-\mathrm{H}$ valence vibration; (B) $\mathrm{C}-\mathrm{H}$ valence vibration; (C) $\mathrm{C}=\mathrm{O}$ valence vibration; (D) $\mathrm{CH}_{2}$ deformation vibration; (E) $\mathrm{C}-\mathrm{O}$ valence vibration. 


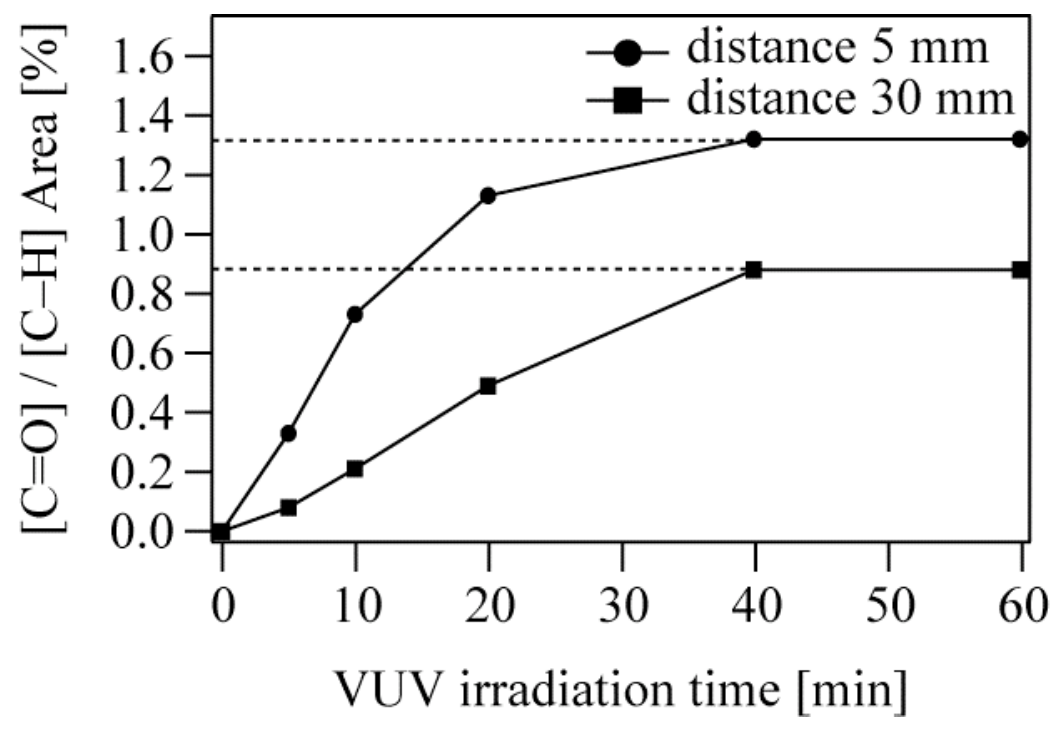

Fig. 8. Carbonyl band (1897-1519 $\mathrm{cm}^{-1}$, valence vibration), relative to hydrocarbon band (3050-2750 $\mathrm{cm}^{-1}$, valence vibration) area, as a function of the time for VUV irradiation. 

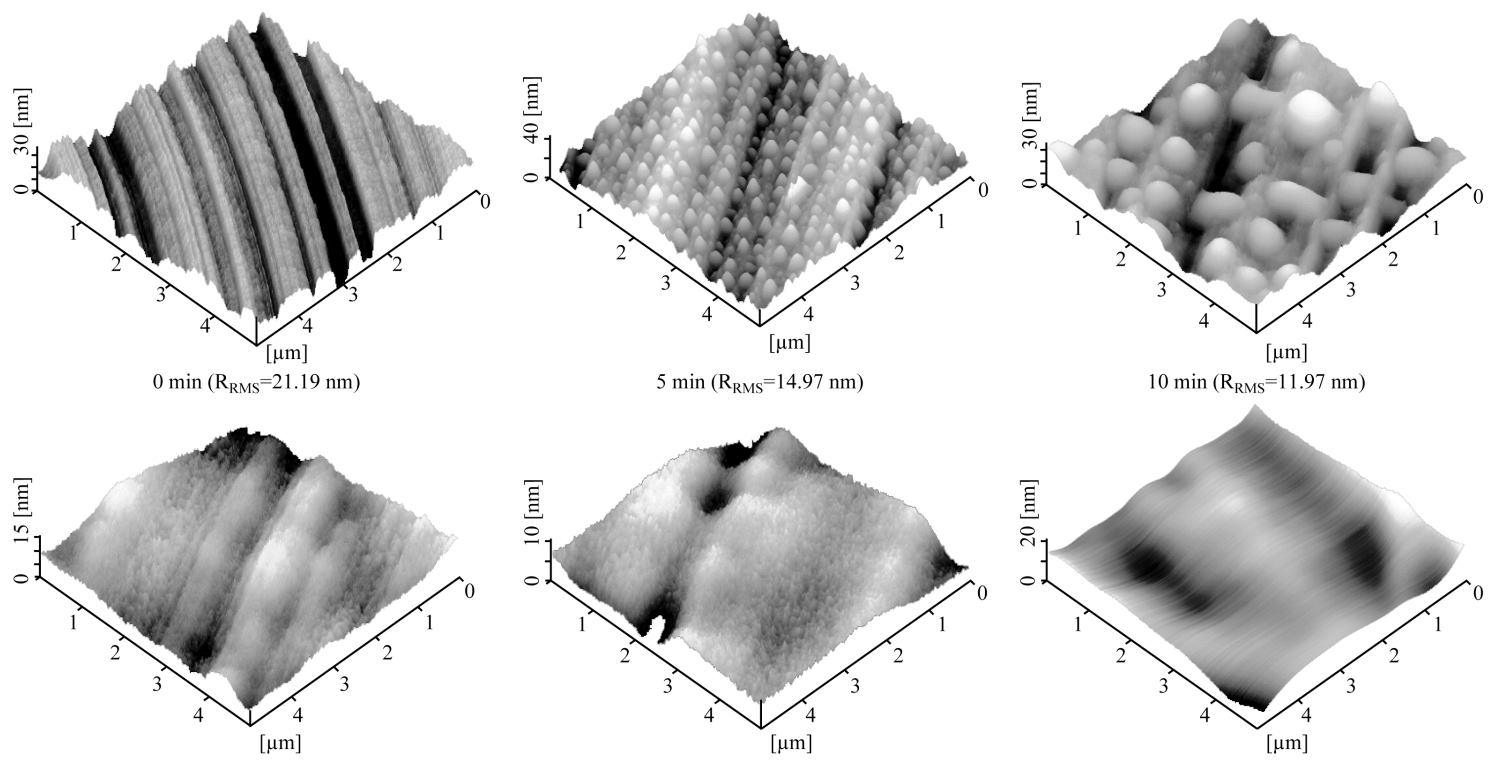

$20 \min \left(\mathrm{R}_{\mathrm{RMS}}=2.75 \mathrm{~nm}\right)$

$40 \min \left(\mathrm{R}_{\mathrm{RMS}}=2.01 \mathrm{~nm}\right)$

$60 \min \left(R_{\mathrm{RMS}}=1.64 \mathrm{~nm}\right)$

Fig. 9. AFM topography images and RMS roughness on COP surfaces of distance $5 \mathrm{~mm}$ before and after irradiation with VUV light for 5 - $60 \mathrm{~min}$ (tapping mode; image size, $5 \times 5 \mu^{2}$ ). 

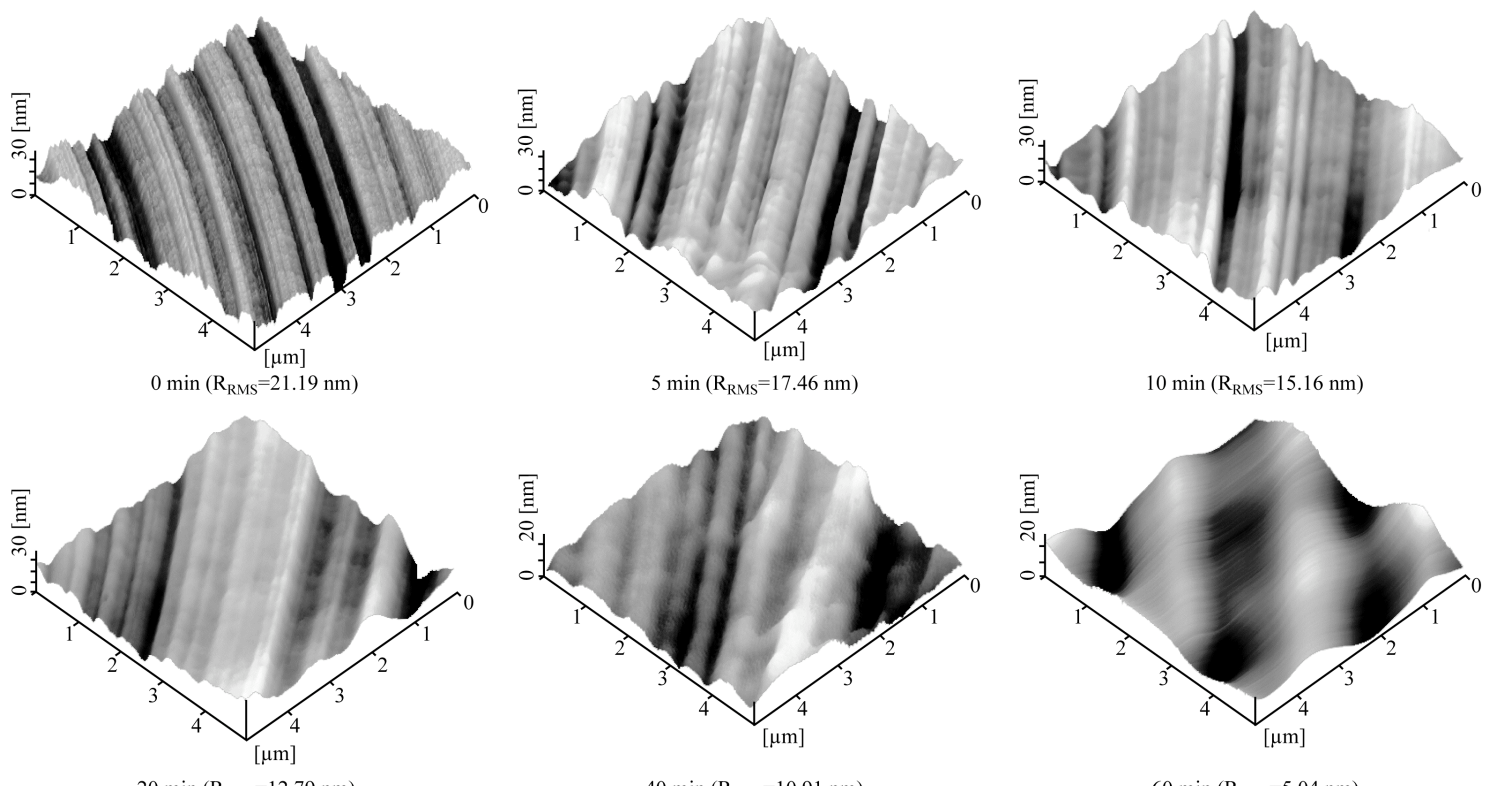

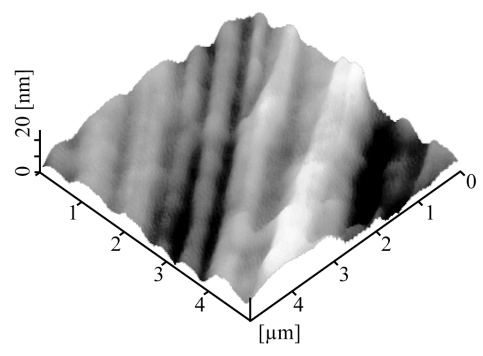

$40 \min \left(\mathrm{R}_{\mathrm{RMS}}=10.91 \mathrm{~nm}\right)$

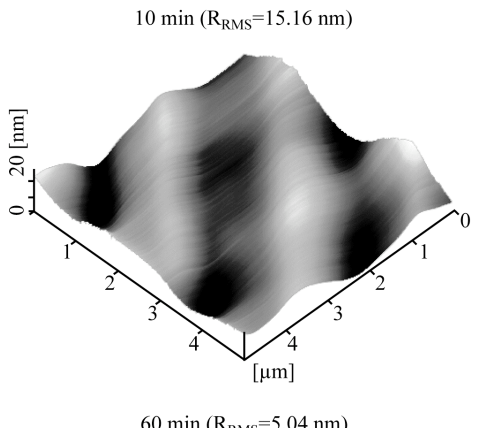

$60 \min \left(R_{R M S}=5.04 \mathrm{~nm}\right)$

Fig. 10. AFM topography images and RMS roughness on COP surfaces of distance $30 \mathrm{~mm}$ before and after irradiation with VUV light for 5 - $60 \mathrm{~min}$ (tapping mode; image size, $5 \times 5 \mu^{2}$ ). 
Table I. Atomic percentages of four elements including C 1s of different carbon moieties determined by XPS versus VUV-light treatment time for distance $5 \mathrm{~mm}$.

\begin{tabular}{|c|c|c|c|c|c|}
\hline \multirow{2}{*}{$\begin{array}{l}\text { VUV-light } \\
\text { treatment } \\
\text { time [min] }\end{array}$} & \multicolumn{4}{|c|}{$\mathrm{C}[\%]$} & \multirow{2}{*}{$\mathrm{O}[\%]$} \\
\hline & $\mathrm{C}-\mathrm{H}[\%]$ & $\mathrm{C}-\mathrm{O}[\%]$ & $\mathrm{C}=\mathrm{O}[\%]$ & $\mathrm{COO}[\%]$ & \\
\hline 0 & 94 & 3 & - & - & 3 \\
\hline 5 & 59 & 7 & 7 & 3 & 24 \\
\hline 10 & 37 & 6 & 13 & 6 & 38 \\
\hline 20 & 33 & 7 & 13 & 7 & 40 \\
\hline 40 & 30 & 7 & 15 & 7 & 41 \\
\hline 60 & 30 & 7 & 15 & 7 & 41 \\
\hline
\end{tabular}


Table II. Atomic percentages of four elements including C 1s of different carbon moieties determined by XPS versus VUV-light treatment time for distance $30 \mathrm{~mm}$.

\begin{tabular}{|c|c|c|c|c|c|}
\hline \multirow{2}{*}{$\begin{array}{l}\text { VUV-light } \\
\text { treatment } \\
\text { time [min] }\end{array}$} & \multicolumn{4}{|c|}{$\mathrm{C}[\%]$} & \multirow{2}{*}{$\mathrm{O}[\%]$} \\
\hline & $\mathrm{C}-\mathrm{H}[\%]$ & $\mathrm{C}-\mathrm{O}[\%]$ & $\mathrm{C}=\mathrm{O}[\%]$ & $\mathrm{COO}[\%]$ & \\
\hline 0 & 94 & 3 & - & - & 3 \\
\hline 5 & 82 & 3 & 3 & - & 12 \\
\hline 10 & 71 & 3 & 6 & 1 & 19 \\
\hline 20 & 51 & 9 & 9 & 3 & 28 \\
\hline 40 & 47 & 9 & 9 & 4 & 31 \\
\hline 60 & 48 & 9 & 9 & 4 & 30 \\
\hline
\end{tabular}

